\author{
Alireza Shamsi', Hooria Yavarmanesh², Hani Harati , Shiva Eiliaei', Majid Sadeghian ${ }^{1}$ \\ 'School of Medicine, Shahid Beheshti University of Medical Sciences, Tehran, Iran \\ ${ }^{2}$ Faculty of Medicine, Zahedan University of Medical Sciences, Zahedan, Iran \\ ${ }^{3}$ Department of Cardiology, Ali Ibn Abi Talib Hospital, Faculty of Medicine, \\ Zahedan University of Medical Sciences, Zahedan, Iran
}

\title{
The relationship between medication adherence and affective temperaments in patients with congestive heart failure
}

\begin{abstract}
Introduction: Congestive heart failure (CHF) is a serious condition and lack of medication adherence is one of the most common problems in the treatment of patients with CHF. This study aimed to determine the relationship between medication adherence and affective temperaments in patients with CHF.

Material and methods: This cross-sectional study was performed on 150 patients, who were referred to the cardiology clinic of Ali Ibn Abi Talib Hospital of Zahedan, Iran in 2017-2018. Morisky Medication Adherence Scale (MMAS-8), Temperament Evaluation of Memphis, Pisa, Paris, and San Diego auto questionnaire (TEMPS-A), and Beck Depression Inventory-II (BDI-II) were used to collect data. For statistical analysis, SPSS-18 was used. Logistic regression was done for modeling the relationship between medication adherence.

Results: Generally, 54\% of the patients were euthymic, while $16 \%, 23.33 \%$, and $6.66 \%$ of them suffered from mild, moderate, and severe depression, respectively. The medication adherence was high, moderate, and low in 30.66\%, $46 \%$, and $23.33 \%$ of the patients, respectively. There was a significant relationship between medication adherence and depressive $(P=0.049)$, cyclothymic $(P=0.01)$, and irritable $(P=0.01)$ affective temperaments. Only BDI-Il score $(P=$ 0.018) was identified as predictors of drug adherence.

Conclusions: Despite the statistically significant relationship between depressive, cyclothymic, and irritable temperaments and adherence, affective temperaments cannot be considered as a predictor of adherence in patients with CHF. Psychiatry 2020; 17, 3: 115-120
\end{abstract}

Key words: medication adherence, congestive heart failure, affective temperaments, depression

\begin{abstract}
Introduction
Cardiovascular diseases are one of the most common chronic diseases worldwide, which are known as one of the main causes of morbidity and mortality [1, 2]. Congestive heart failure (CHF) is a chronic progressive condition, which is associated with the inefficiency of the heart in pumping and maintaining the blood flow [1]. According to the American Heart Association (AHA), about 5.8 million people in the USA and 22 million people worldwide suffer from heart failure. In addition,
\end{abstract}

Adres do korespondencji:

Alireza Shamsi

School of Medicine

Shahid Beheshti University

of Medical Sciences, Tehran, Iran

e-mail: ar.shamsi@sbmu.ac.ir
550,000 people are annually diagnosed with $\operatorname{CHF}[3,4]$. As the rate of $\mathrm{CHF}$ increases, it imposes heavy costs on the health systems [4].

The treatment process of patients with heart failure is difficult because of the complex and diverse medication regimens used for these patients [5]. Previous studies showed that about half of CHF patients do not comply with the regimens prescribed by their physicians, which can lead to devastating consequences and their rehospitalization [6].

Some factors such as hyperlipidemia, hypertension, high body mass index (BMI), diabetes mellitus, thyroid disorders, and health-related behaviors such as smoking and alcohol use play a major role in the incidence of cardiovascular diseases; these conditions may also affect the 
treatment process in CHF patients [7]. In some patients with asymptomatic cardiac dysfunction, medication non-adherence can lead to disease development and exacerbation [8]. After identification of the risk factors for heart failure, great attention has been focused on medication adherence and self-care behaviors in recent years $[9,10]$.

On the other hand, personality characteristics are a main important factor affecting the self-care behaviors of individuals [11]. Behavioral researchers have focused on the role of psychological factors and problems such as stress, tension, anxiety, depression, and type A behavior pattern on CHF [12]. Furthermore, they assessed other personality characteristics contributing to the incidence of $\mathrm{CHF}$ in addition to the classical elements [13]. Recent studies have highlighted the role of affective factors such as anger, hostility, depression, and anxiety in the development and progression of CHF [14]. As a result, personality characteristics are closely related to physical health [15].

Personality bridging inborn temperamental and learned characterological features associated with psychological and behavioral traits. Temperament is closer to "humoral theory" and represents the biological core of personality with the genetic and constitutional endowment. Character is more linked to nurturing, comprising acquired competencies during development, namely interpersonal development [16]. Some of the previous studies have revealed that medication adherence is been influenced by personality characteristics such as affective temperaments [17].

Considering the high importance of $\mathrm{CHF}$ and the limited number of studies examining the relationship between affective temperaments and medication adherence, this study aimed to determine the relationship between affective temperaments and medication adherence in patients with $\mathrm{CHF}$.

\section{Material and methods}

This cross-sectional study was performed on patients referred to the cardiology clinic of Ali Ibn Abi Talib Hospital of Zahedan, Iran in 2017 and 2018 with the diagnosis of CHF. By using the available sampling method, 156 patients were included in the study. First, the patients who met the inclusion criteria were selected. Of 156 participants, 6 patients with incomplete questionnaires were excluded from the study. At the end, 150 subjects were enrolled in the study.

\section{Inclusion and exclusion criteria}

The inclusion criteria were as follows: 1 ) age $\geq 18$ years; 2) diagnosis of CHD based on patient's clinical record;
3) at least three months elapsed from the diagnosis of $\mathrm{CHF}$; 4) presence of New York Heart Association (NYHA) class II or III symptoms based on patient's clinical record; 5) left ventricular ejection fraction (LVEF) $\leq 45 \%$; 6 ) the number of medications taken daily for the treatment of $\mathrm{CHF} \leq 5 ; 7)$ proficiency in reading and writing Persian; and 8) providing informed consents.

Patients with severe cognitive problems, LVEF greater than $45 \%$, and NYHA class I or IV symptoms were excluded from the study. Lack of patient's consent to participate in the study was another exclusion criterion.

\section{Data collection tools}

\section{Morisky Medication Adherence Scale (MMAS-8)}

Morisky Medication Adherence Scale (MMAS-8) is a structured, self-reported medication adherence measure [18]. This scale had been used to evaluate medication adherence in patients with heart failure [19]. The MMAS- 8 has 8 items. Response choices for items 1 to 7 are "Yes" or "No". The 8th Item is a Likert-type question. The total score ranges from 0 to 8 . Scores of less than 6 indicate low adherence, scores of 6 to $<8$ indicate moderate adherence and score $=8$ indicates high adherence. To perform logistic regression, patients with scores less than 6 were considered as patients with non-adherence, and patients with scores of 6 and higher were considered as patients with adherence. The Persian version of MMAS-8, that has been used in the present study, validated by Moharamzad et.al. in 2015 [20].

\section{TEMPS- $A$}

To assess the patients' affective temperaments, we used the Temperament Evaluation of Memphis, Pisa, Paris, and San Diego Auto questionnaire (TEMPS-A).

This questionnaire was designed by Akiskal et al. [21] to assess five affective temperaments including depressive, cyclothymic, hyperthymic, irritable, and anxious temperaments.

In the present study, we usedv a brief Persian version of TEMPS-A which is validated in Persian language [22]. This version of TEMPS-A consists of 35 yes/no items and the score ranges from 0 to 1 for each temperament.

\section{Beck Depression Inventory-II (BDI-II)}

Beck Depression Inventory was designed by Aaron T. Beck. This instrument is a 21 -item, multiple-choice, selfreport inventory, which is used for measuring the severity of depression among patients. It consists of items related to depression symptoms (hopelessness and irritability), cognition (guilt or feelings of being punished), and physical symptoms (fatigue, weight loss, and lack of interest in 
sex). BDI-II is a revision of $\mathrm{BDI}$, designed in 1996. BDI-II is validated in Persian language [23].

\section{Ethical considerations}

The present study was approved by the Ethics Committee of Zahedan University of Medical Sciences. All the participants were assured in terms of data confidentiality and informed consent were obtained from all subjects.

\section{Data analysis}

All participants in this study completed the questionnaire related to medication adherence, affective temperaments, and depression. Afterward, the obtained data were recorded on the prepared sheets. The collected data were entered into SPSS version 18. The distribution of samples and comparison of quantitative variables were evaluated by the Kolmogorov-Smirnov test, t-test, and Man-Whitney test. The comparison of qualitative variables was performed by the Chi-square test. Also, logistic regression was used for modeling the relationship between medication adherence and the associated variables.

\section{Results}

In general, $54.66 \%$ of the patients were female, and the mean age of the patients was $48.48 \pm 12.25$ years.
In terms of marital status, $7.33 \%, 74.66 \%, 8 \%$, and $10 \%$ of the patients were single, married, divorced, and widowed, respectively. Moreover, 20\%, 23.33\%, 18\%, and $1.33 \%$ of the patients had a high school, associate degree, bachelor's degree, and master's degree, respectively; The remainder of the subjects had basic education. The level of medication adherence was high, moderate, and low in $30.66 \%, 46 \%$, and $23.33 \%$ of the patients, respectively.

BDI-II showed that $54 \%$ of the patients were euthymic, whereas $16 \%, 23.33 \%$, and $6.66 \%$ of them suffered from mild, moderate, and severe depression, respectively. The mean depressive temperament score was $0.562 \pm$ 0.16 . Moreover, the mean temperament scores were $0.447 \pm 0.298,0.508 \pm 0.19,0.305 \pm 0.194$, and $0.56 \pm 0.228$ in cyclothymic, hyperthymic, irritable, and anxious temperaments, respectively.

The comparison of medication adherence in CHF patients based on gender, marriage statues educational level, and severity of depression are shown in Table 1.

For evaluating the relationships between affective temperaments, BDI-II score, and medication adherence were examined by t-test and Mann-Whitney test. According to the obtained results, BDI-II score, depressive, cyclothymic, and irritable temperaments were inversely related to medication adherence. However, there was no significant

Table 1. The comparison of demographic characteristics and depression of patients with high, moderate, and low medication adherence

\begin{tabular}{|c|c|c|c|c|c|c|}
\hline & & \multirow[t]{3}{*}{ Total } & \multicolumn{3}{|c|}{ Medication adherence } & \multirow[t]{3}{*}{ P-value } \\
\hline & & & High & Moderate & Low & \\
\hline & & & $30.66 \%$ & $46 \%$ & $23.33 \%$ & \\
\hline \multirow[t]{2}{*}{ Gender } & Male & $45.33 \%$ & $28.4 \%$ & $44.8 \%$ & $26.9 \%$ & \multirow[t]{2}{*}{0.519} \\
\hline & Female & $54.66 \%$ & $33.7 \%$ & $47 \%$ & $19.3 \%$ & \\
\hline \multirow{4}{*}{$\begin{array}{l}\text { Marriage } \\
\text { statues }\end{array}$} & Single & $7.33 \%$ & $22.2 \%$ & $22.2 \%$ & $55.6 \%$ & \multirow[t]{4}{*}{0.029} \\
\hline & Married & $74.66 \%$ & $32.7 \%$ & $49.6 \%$ & $17.7 \%$ & \\
\hline & Divorced & $8 \%$ & $23.1 \%$ & $23.1 \%$ & $53.8 \%$ & \\
\hline & Widow & $10 \%$ & $33.3 \%$ & $53.3 \%$ & $13.3 \%$ & \\
\hline \multirow[t]{5}{*}{ Education } & Basic & $37.33 \%$ & $31 \%$ & $55.2 \%$ & $13.8 \%$ & \multirow[t]{5}{*}{0.001} \\
\hline & High school & $20 \%$ & $30 \%$ & $46.7 \%$ & $23.3 \%$ & \\
\hline & Associate diploma & $23.33 \%$ & $47.1 \%$ & $44.1 \%$ & $8.8 \%$ & \\
\hline & Bachelor & $18 \%$ & $14.8 \%$ & $29.6 \%$ & $55.6 \%$ & \\
\hline & Master's degree & $1.33 \%$ & 0 & 0 & $100 \%$ & \\
\hline \multirow{4}{*}{$\begin{array}{l}\text { Depres- } \\
\text { sion }\end{array}$} & Normal & $54 \%$ & $49 \%$ & $40.8 \%$ & $10.2 \%$ & \multirow[t]{4}{*}{0.001} \\
\hline & Mild & $16 \%$ & $10 \%$ & $50 \%$ & $40 \%$ & \\
\hline & Moderate & 23.33 & $27.3 \%$ & $33.3 \%$ & $39.4 \%$ & \\
\hline & Severe & $6.66 \%$ & $25 \%$ & $58.3 \%$ & $16.7 \%$ & \\
\hline
\end{tabular}


Table 2. The comparison between affective temperaments and BDI-II scores based on low, moderate, and high medication adherence

\begin{tabular}{|c|c|c|c|c|}
\hline & \multicolumn{3}{|c|}{ Medication Adherence } & \multirow[t]{2}{*}{ P-value } \\
\hline & High & Moderate & Low & \\
\hline Depressive Temperament & $0.521 \pm 0.185$ & $0.597 \pm 0.137$ & $0.552 \pm 0.155$ & 0.049 \\
\hline Cyclothymic Temperament & $0.339 \pm 0.22$ & $0.503 \pm 0.183$ & $0.483 \pm 0.188$ & 0.01 \\
\hline Hyperthymic Temperament & $0.574 \pm 0.194$ & $0.459 \pm 0.189$ & $0.521 \pm 0.163$ & 0.11 \\
\hline Irritable Temperament & $0.225 \pm 0.185$ & $0.313 \pm 0.195$ & $0.384 \pm 0.169$ & 0.01 \\
\hline Anxious Temperament & $0.453 \pm 0.266$ & $0.599 \pm 0.215$ & $0.533 \pm 0.198$ & 0.218 \\
\hline BDI-II Score & $11.3 \pm 8.2$ & $15.1 \pm 7.9$ & $18.5 \pm 9.9$ & 0.001 \\
\hline
\end{tabular}

relationship between medication adherence and anxious and hyperthymic temperaments (Table 2).

For modeling the relationships between medication adherence and the related variables, logistic regression analysis was used. To determine the association between drug adherence and gender, age, depression, and temperaments, multiple correlation coefficient $(R=0.358)$, coefficient of determination ( $R 2=0.128$ ), pure determination coefficient $(R-2=0.104)$, and standard error of estimate ( $\mathrm{SEE}=1.529$ ) were calculated. According to the obtained results, about $12 \%$ of the medication adherence variance score was explained by effective predictor variables; therefore, the regression was linear $(F=5.342 ; P>0.005)$.

Simultaneous regression analysis showed that only BDI-II scores $(P=0.018)$ were identified as predictors of drug adherence. Age, gender, and temperament variables could not predict medication adherence (Table 3).

\section{Discussion}

According to the results of the present study, high medication adherence was observed in less than one-third of the cases. About half of the patients showed moderate medication adherence, and low medication adherence was observed in more than one-fifth of cases.

This study reflected a significant linear relationship between depression, depressive temperament, cyclothymic temperament, and irritable temperament with drug adherence. Our results demonstrated a lack of predictive power of different temperaments on medication adherence in CHF patients.

Non-adherence is a common problem among CHF patients [24-26]. Previous studies have been conducted about the causes of non-adherence with treatments. Some of these studies have examined the relationship between psychological factors and medication adherence. For the first time, lack of response to treatment due to non-adherence with drug and dietary regimens was introduced as the main risk factor in patients with heart failure by Ghali et al. [27]. Based on the study by Lennie et al., non-adherence with dietary regimen was observed in three-quarters of CHF patients [26]. This finding is like the results of the present study in which only $31.3 \%$ of patients had high medication adherence. Additionally, our results are in accordance with those of Parsa-Yekta et al. [28] study, in which the rate of drug adherence was estimated at $28 \%$ in CHF patients and poor drug adherence was observed in the majority of patients with $\mathrm{CHF}$.

However, the rate of medication adherence was higher in the study by Jahanpour et al. [29]. This discrepancy might be due to different study designs, different demographic characteristics, and different methods for evaluating drug adherence. On the other hand, the bias in the selection of patients in our study might have affected drug adherence rate, as our study was performed on the patients presented to the cardiology clinic and moderate symptoms (NYHA class II or III); therefore, it cannot be an accurate reflection of the CHF patients' population.

Ghali et al. found that low adherence to treatment was higher in males than the females [27], which is inconsistent with our result. However, like our study, Hadian and Mokhbery did not show any significant difference in medication adherence between the two genders [30], which was confirmed by the other similar studies $[29,31]$. According to our findings, there was no statistically significant relationship between age and drug adherence. Some studies have shown that elderly patients may lack self-care and medication adherence behaviors due to disabilities of aging and problems such as cognitive problems [32]. Medication adherence was better in married patients than the single subjects, which was confirmed by other studies $[5,28]$. One reason may be a higher prevalence of psychiatric disorders in single or divorced patients compared to married ones and these disorders can decrease medication adherence. 
Table 3. The relationship between demographic data, depression, and affective temperaments with medication adherence

\begin{tabular}{|c|c|c|c|c|c|}
\hline \multirow[t]{2}{*}{ Model } & \multicolumn{2}{|c|}{$\begin{array}{l}\text { Unstandardized } \\
\text { coefficients }\end{array}$} & \multirow{2}{*}{$\begin{array}{c}\begin{array}{c}\text { Standardized } \\
\text { coefficients }\end{array} \\
\text { Beta }\end{array}$} & \multirow[t]{2}{*}{ T-test } & \multirow[t]{2}{*}{ P-value } \\
\hline & Beta & SEm* & & & \\
\hline Fixed amount & 1.534 & 0.837 & & 1.834 & 0.069 \\
\hline Gender & 0.376 & 0.257 & 0.116 & 1.462 & 0.146 \\
\hline Age & -0.03 & 0.01 & -0.225 & -2.894 & 0.059 \\
\hline Depression & 0.031 & 0.013 & 0.232 & 0.387 & 0.018 \\
\hline Affective temperament (total) & 0.007 & 0.011 & 0.062 & 0.629 & 0.531 \\
\hline
\end{tabular}

*Standard error of measurement

Our study demonstrated that medication adherence is low in depressed patients, which can be justified considering low motivation of patients for treatment. According to the obtained results, logistic regression did not reflect any predictive association between affective temperaments and medication adherence. Hall et al. [33] showed that the anxious temperament can facilitate the diagnosis of diabetes in the early stages of the disease; however, similar to our findings, there was no significant relationship between the anxious temperament and selfcare in diabetic patients at 6-month follow-up.

These findings were inconsistent with the obtained results of Shamsi et al. [17]. They showed that the irritable temperament was a predictor of drug adherence. This may be as a result of the differences in sample characteristics or sample size. Also, the patients in our study suffered from CHF, while the study of Shamsi et al. was performed on the patients with diabetes.

\section{Conclusion}

Very few studies have been conducted about the relationship affective temperaments and medication adherence in patients with CHF. This may reflect the lack of attention to the relationship between medication adherence and personality characteristics and further studies in this area in the future can help clarify different aspects of this relationship and are therefore suggested. According to the findings of the present study, affective temperaments cannot be considered as a predictor of adherence in patients with CHF.

\section{Limitations and strengths}

In this study, the relationship between medication adherence and affective temperaments was assessed. In fact, no similar studies have been conducted in the Iranian population.

We used available sampling methods for subject selection, thus, future studies in other centers and with larger sample sizes are recommended.
Given this study was carried out on patients referred to cardiology clinic, it cannot be an accurate reflection of the CHF patients' population, therefore, future studies are recommended in this regard.

\section{References:}

1. Mendis S, Puska P, Norrving B. Global atlas on cardiovascular disease prevention and control: World Health Organization; 2011.

2. Khoshtarash M, Momeni M, Ghanbari A, et al. Self-care behaviors and related factors in patients with heart failure reffering to medical \& educational center of heart in Rasht. Holistic Nursing and Midwifery Journal. 2013; 23(1): 22-9.

3. Labarthe DR. Epidemiology and prevention of cardiovascular diseases: a global challenge. Jones \& Bartlett Publishers 2010.

4. Lloyd-Jones D, Adams RJ, Brown TM, et al. American Heart Association Statistics Committee and Stroke Statistics Subcommittee, WRITING GROUP MEMBERS, American Heart Association Statistics Committee and Stroke Statistics Subcommittee. Heart disease and stroke statistics - 2010 update: a report from the American Heart Association. Circulation. 2010; 121(7): e46-e4e215, doi: 10.1161/ CIRCULATIONAHA.109.192667, indexed in Pubmed: 20019324.

5. Bennett SJ, Lane KA, Welch J, et al. Medication and dietary compliance beliefs in heart failure. West J Nurs Res. 2005; 27(8): 977-994, doi: 10.1177/0193945905280253, indexed in Pubmed: 16275694.

6. Venner GH, Seelbinder JS. Team management of congestive heart failure across the continuum. J Cardiovasc Nurs. 1996; 10(2): 71-84, doi: 10.1097/00005082-199601000-00007, indexed in Pubmed: 8656239.

7. Kapfhammer HP. [The relationship between depression, anxiety and heart disease - a psychosomatic challenge]. Psychiatr Danub. 2011; 23(4): 412-424, indexed in Pubmed: 22075746.

8. Philbin EF, DiSalvo TG. Influence of race and gender on care process, resource use, and hospital-based outcomes in congestive heart failure. Am J Cardiol. 1998; 82(1): 76-81, doi: 10.1016/s00029149(98)00233-1, indexed in Pubmed: 9671013.

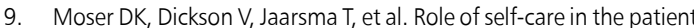
with heart failure. Curr Cardiol Rep. 2012; 14(3): 265-275, doi: 10.1007/s11886-012-0267-9, indexed in Pubmed: 22437374.

10. González B, Lupón J, Herreros J, et al. Patient's education by nurse: what we really do achieve? Eur J Cardiovasc Nurs. 2005; 4(2): 107-111, doi: 10.1016/j.ejcnurse.2005.03.006, indexed in Pubmed: 15904880

11. Lloyd G, Guthrie E. Handbook of liaison psychiatry. Cambridge University Press 2007

12. McMurray J. Why we need new strategies in CHF management. J Renin Angiotensin Aldosterone Syst. 2000; 1 Suppl 1: 12-16, doi: 10.3317/JRAAS.2000.027, indexed in Pubmed: 11967787.

13. Rosenström T, Jokela M, Cloninger CR, et al. Associations between dimensional personality measures and preclinical atherosclerosis: the cardiovascular risk in Young Finns study. J Psychosom Res. 2012; 72(5): 336-343, doi: 10.1016/j.jpsychores.2012.02.003, indexed in Pubmed: 22469275. 
14. Nefs G, Speight J, Pouwer F, et al. DS14: standard assessment of negative affectivity, social inhibition, and Type $D$ personality. Psychosom Med. 2005; 67(1): 89-97, doi: 10.1097/01. psy.0000149256.81953.49, indexed in Pubmed: 15673629.

15. Kring A, Davison G, Johnson S. Abnormal Psychology (Psychology of Abnormality). Shamsi Pour H(Persian translator. 2010; 2: 241-68.

16. Gois $C$, Barbosa A, Ferro A, et al. The role of affective temperaments in metabolic control in patients with type 2 diabetes. J Affect Disord. 2011; 134(1-3): 52-58, doi: 10.1016/j.jad.2011.05.021, indexed in Pubmed: 21641045.

17. Shamsi A, Khodaifar F, Arzaghi SM, et al. Is there any relationship between medication compliance and affective temperaments in patients with type 2 diabetes? J Diabetes Metab Disord. 2014 13(1): 96, doi: 10.1186/s40200-014-0096-z, indexed in Pubmed: 25276668.

18. Morisky DE, Ang A, Krousel-Wood M, et al. Predictive validity of a medication adherence measure in an outpatient setting. J Clin Hypertens (Greenwich). 2008; 10(5): 348-354, doi: 10.1111/j.1751-7176.2008.07572.x, indexed in Pubmed: 18453793

19. Granger BB, Ekman I, Hernandez AF, et al. Results of the Chronic Heart Failure Intervention to Improve MEdication Adherence study: A randomized intervention in high-risk patients. Am Heart J. 2015; 169(4): 539-548, doi: 10.1016/j.ahj.2015.01.006, indexed in Pubmed: 25819861.

20. Moharamzad $Y$, Saadat $H$, Nakhjavan Shahraki B, et al. Validation of the Persian Version of the 8-Item Morisky Medication Adherence Scale (MMAS-8) in Iranian Hypertensive Patients. Glob J Health Sci. 2015; 7(4): 173-183, doi: 10.5539/gjhs.v7n4p173, indexed in Pubmed: 25946926.

21. Yoda N, Yamashita T, Wada Y, et al. Classification of adult patients with type 2 diabetes using the Temperament and Character Inventory. Psychiatry Clin Neurosci. 2008; 62(3): 279-285, doi: 10.1111/j.1440-1819.2008.01794.x, indexed in Pubmed: 18588587.

22. Khalili N, Panjalizadeh $M$, Jahani $Y$, et al. Validation of the brief persian version of the affective temperament auto-questionnaire TEMPS-A. Iranian Journal of Psychiatry and Clinical Psychology. 2018; 24(1): 92-107, doi: 10.29252/nirp.ijpcp.24.1.92.

23. Ghassemzadeh $\mathrm{H}$, Mojtabai R, Karamghadiri N, et al. Psychometric properties of a persian-language version of the beck depression inventory - second edition: BDI-II-PERSIAN. Depress Anxiety. 2005; 21(4): 185-192, doi: 10.1002/da.20070, indexed in Pubmed: 16075452.

24. Abbasi M, Salemi S, Fatemi NS, et al. Hypertensive patients, their compliance level and its' relation to their health beliefs. Iran Journal of Nursing. 2005; 18(41): 61-8.

25. Monane M, Bohn RL, Gurwitz JH, et al. Noncompliance with congestive heart failure therapy in the elderly. Arch Intern Med. 1994; 154(4): 433-437, indexed in Pubmed: 8117176.

26. Lennie TA. Nutrition self-care in heart failure: state of the science. J Cardiovasc Nurs. 2008; 23(3): 197-204, doi: 10.1097/01. JCN.0000317426.14092.60, indexed in Pubmed: 18437060.

27. Ghali JK, Kadakia S, Cooper R, et al. Precipitating factors leading to decompensation of heart failure. Traits among urban blacks. Arch Intern Med. 1988; 148(9): 2013-2016, indexed in Pubmed: 3046541.

28. Parsa-Yekta Z, Zakeri Mo, Mehran A et al. Study of medication compliance of patients with coronary heart diseases and associated factors. Journal of Hayat. 2004; 9(4): 34-43.

29. Jahanpour F, Rafiei Z, Ravanipour $M$, et al. Assessment of medication adherence in elderly patients with cardiovascular diseases based on demographic factors in Bushehr City in the year 2013. Jundishapur Journal of Chronic Disease Care. 2015; 4(3), doi: $10.5812 / j$ jicdc.28399v2.

30. Hadian K, Mokhbery V. Assessment and Identification of Precipitating Factors of Heart Failure in 140 patients In Immam Khomeini Hospital of Sari in 1376-77. Journal of Mazandaran University of Medical Sciences. 1999; 9(24): 24-31.

31. Ho PM, Rumsfeld JS, Masoudi FA, et al. Effect of medication nonadherence on hospitalization and mortality among patients with diabetes mellitus. Arch Intern Med. 2006; 166(17): 1836-1841, doi: 10.1001/archinte.166.17.1836, indexed in Pubmed: 17000939.

32. Pugh MJo, Anderson J, Pogach LM, et al. Differential adoption of pharmacotherapy recommendations for type 2 diabetes by generalists and specialists. Med Care Res Rev. 2003; 60(2): 178-200, doi: 10.1177/1077558703060002003, indexed in Pubmed: 12800683.

33. Hall PA, Rodin GM, Vallis TM, et al. The consequences of anxious temperament for disease detection, self-management behavior, and quality of life in Type 2 diabetes mellitus. J Psychosom Res. 2009; 67(4): 297-305, doi: 10.1016/j.jpsychores.2009.05.015, indexed in Pubmed: 19773022. 